\title{
Pendidikan Kristen dalam Gereja Sebagai Dasar dan Sarana Aktualisasi Misi Kristen
}

\author{
Paulus Purwoto \\ Sekolah Tinggi Teologi Torsina \\ Email: pauluspurwoto022@gmail.com
}

\begin{abstract}
The role of believers and the church in actualizing the mission has a wrong mindset towards the basic concepts of missiology which results in not maximizing the preaching of the good news to others. Some people claim to be Christian but are reluctant to carry out the Great Commission and Paradigm that wrongly denounces the role of believers in evangelizing. For this reason, the church in Christian education is expected to be able to provide understanding to church members to be able to make Christian education the basis and means of evangelism. Using a qualitative descriptive approach, this research can be started by describing the mission and nature of the mission that Christian education must begin with an understanding related to the nature of missiology as the basis and driving force for the mission. Furthermore, the mission in Christian Education must also be a curriculum that is continuously taught to regenerate the Lord's congregation to continue to actualize the mandate of the Great Commission. so that the Church and Mission as a source of actualization can be realized and become the lifestyle of believers as part of the church.
\end{abstract}

Keyword: Evangelism, Christian Education, Great Commission, Mission Actualization, Motivation.

\begin{abstract}
Abstrak
Peran orang percaya dan gereja dalam mengaktualisasi misi memiliki mindset yang salah terhadap konsep dasar misiologi yang mengakibatkan tidak maksimalnya pemberitaan kabar baik bagi orang lain. Adanya orang yang mengaku Kristen, tetapi enggan untuk melakukan Amanat Agung dan Paradigma yang salah mengakibatkan tidak maksimalnya peran orang percaya dalam menginjil. Untuk itu, tujuan dari penelitian ini adalah agar gereja dalam pendidikan Kristen diharapkan mampu memberikan pemahaman kepada anggota gereja untuk dapat menjadikan pendidikan Kristen sebagai dasar dan sarana penginjilan. Menggunakan pendekatan kualitatif deskriptif penelitian ini dimulai dengan mendeskripsikan misi dan hakikat misi, selanjutnya pendidikan Kristen yang dimulai dengan pengertian yang berkaitan terhadap konsep dasar Misiologi sebagai motivasi atau penggerak dalam melakukan misi. Dan misi dalam Pendidikan Kristen juga harus menggunakan kurikulum misi yang terus diajarkan untuk meregenerasi jemaat Tuhan untuk terus mengaktualisasi mandat Amanat Agung. sehingga gereja dan misi sebagai sumber Aktualisasi dapat terwujud dan menjadi gaya hidup orang percaya sebagai bagian dari gereja.
\end{abstract}

Kata Kunci: Penginjilan, Pendidikan Kristen, Amanat Agung, Aktualisasi Misi, Motivasi. 


\section{PENDAHULUAN}

Tugas gereja dalam misi adalah hal yang utama untuk mengaktualisasi mandat amanat Agung Tuhan Yesus Kristus (Sunquist 2013). Dengan kerangka berpikir tersebut setiap orang percaya harusnya menjadikan tugas Amanat Agung sebagai tugas penting. Peran gereja sangat dibutuhkan untuk memperkenalkan dan memperlengkapi para anggotanya menjadi generasi yang mengedepankan jiwa-jiwa. Hal itu selaras dengan keinginan Tuhan Yesus untuk menyelamatkan manusia dari maut. Namun demikian masih ditemukan beberapa gereja yang terlalu memfokuskan pelayanan internal gereja sehingga kurang berminat untuk melakukan amanat Agung Kristus. Terlebih adanya paradigma yang salah bagi orang awam bahwa penginjilan dan segala hal berkaitan dengan misi Allah dalam penyelamatan jiwa hanya menjadi bagian para pendeta atau pemimpin gereja lainnya saja (Arifianto, Agung, and Tamtomo 2020). Terdapat fakta dalam gereja bahwa dalam diri orang percaya, terjadi gejala kurang berminat terhadap Amanat Agung. Kebanyakan orang Kristen menjadikan Amanat Agung sebagai tugas yang tidak penting (Arifianto, Triposa, and Lembongan 2020). Terlebih lagi, tidak sedikit orang
Kristen yang memiliki cara pandang yang salah terhadap Amanat Agung. (Arifianto, Oktavia, and Dwikoryanto 2020). Hal ini disebabkan adanya pergeseran paradigma misi, salah satunya oleh karena perkembangan teknologi yang begitu cepat dan masif (Siagian 2016). Persoalan lainya adanya sikap yang berkembang di bangsa ini tentang pemahaman sekaligus sikap curiga dari pemeluk agama lain bahwa misi Kristen identik dengan kristenisasi (Susanta 2020). Dengan demikian, perkembangan penginjilan, menjadi semakin merosot.

Allah memanggil gerejanya untuk satu tugas besar, yakni misi (Mission) (Ott, Strauss, and Tennent 2010). Pengajaran tentang misi dalam gereja merupakan bagian dari faktor utama untuk membentuk jemaat siap mengaktualisasi dan melayani di dalam kegiatan misiologi. Purwoto, Budiana dan Arifianto dalam penelitian terdahulu menulis bahwa bahwa pendidikan Kristen yang baik adalah pendidikan yang mampu menjadi agen amanat Agung Kristus (Purwoto, Budiyana, and Arifianto 2020). Pengajaran yang konsisten, terprogram dan berfokus pada orientasi jiwa-jiwa dapat memberikan pembentukan jemaat yang berkualitas untuk bermisi dalam mengerjakan mandat Amanat Agung. sebab sejatinya Allah memiliki rancangan besar bagi manusia. Rancangan tersebut 
tidak berhenti pada melepaskan manusia dari maut, melainkan terus berproses, sehingga umat Allah serupa dalam Kristus dalam menjadi murid (Matius 28 :19-20) (Sengkoen 2020). John Campebell dan Nelson sebagaimana yang dikutip oleh Siagian mengatakan bahwa gereja sebagai organisasi mempunyai mandate untuk dapat meletakkan dasar moral, etika dan spiritual. Tugas penting inilah yang harusnya menjadi tugas pokok gereja dalam dunia (Siagian 2016).

Dengan latar belakang tersebut peran pendidikan Kristen dalam gereja diharapkan mampu menjawab tantangan misi dengan menjadikan pendidikan Kristen sebagai dasar dan sarana untuk melakukan penginjilan. Sebab Orang Percaya diharapkan dapat memiliki semangat penginjilan yang selaras dengan maksud Allah, namun juga harus mempunyai konsep yang benar tentang teologi misi (Konaniah 2018). Terlebih esensi dari Penginjilan yang ideal adalah penginjilan yang bertumbuh baik secara kualitas maupun kuantitas (Purwoto and Sumiwi 2020), dan meletakan fakta bahwa bersaksi merupakan gaya hidup (Hutahaean 2019). Seperti yang dikatakan oleh Stevanus bahwa penginjilan merupakan tindak aktif dengan manjadi saksi berita Injil bagi orang lain (Stevanus 2020).

\section{METODE PENELITIAN}

Metode penelitian dalam artikel ini adalah penelitian studi pustaka dengan pendekatan kualitatif deskriptif (Umrati and Wijaya 2020:12), yakni penulis akan menggali secara literature/kepustakaan yang berkaitan dengan pendidikan Kristen dalam

gereja sebagai dasar dan sarana aktualisasi misi Kristen. Selain itu penulis, juga menggunakan teks-teks paralel dari buku dan jurnal yang mendukung tentang topik tersebut untuk mendapatkan informasi deskriptif tentang aktualisasi misi Kristen. Sehingga penulis dapat mendeskripsikan topik tersebut sebagai kajian analisis dalam pendidikan Kristen berdasarkan firman Tuhan. Selain menggunakan Alkitab sebagai referensi primer, juga dipergunakan buku-buku dan sumber-sumber primer lain yang relevan dengan topik sesuai prinsip literatur review (S. and Tewksbury 2013).

\section{HASIL DAN PEMBAHASAN}

Allah adalah berita kabar baik itu sendiri bagi umat manusia (David Sills. 2011:45). Kebutuhan akan keselamatan dapat menghancurkan tembok-tembok pemisah antar golongan dan lapisan masyarakat. Serta membuat pertumbuhan jemaat dan meningkatkan pelayanan 
gereja di dunia ini, dengan adanya misi bagi keselamatan jiwa orang lain maka bakat semua orang percaya harus berkembang. Hal itu tidak hanya berlaku untuk fungsi intern di dalam gereja, tetapi juga untuk fungsi ekstern dari gereja ke masyarakat (Jong 2007).

Perkembangan misi mengalami polarisasi dalam upaya pelaksanaannya dalam gereja (Randan Bua et al. 2019). Pengembangan misi perlu untuk terus dilakukan sehingga karya keselamatan Kristus terus dapat dinyatakan (panuntun 2020). Dan menjadi harapan bersama bahwa orang percaya diharapkan dapat memiliki semangat penginjilan yang selaras dengan maksud Allah, namun juga harus mempunyai konsep yang benar tentang teologi misi (Konaniah 2018). Gereja tidak boleh mimasahkan dirinya dari dunia yang majemuk ini merupakan ladang penginjilan (Wongso 1981:129). Sehingga Allah menginginkan gereja-Nya hidup seperti Yesus hidup di dunia ini (Boiliu 2016) (Sagala 2017). Untuk itu gereja dalam hal ini semua orang percaya atau Setiap pribadi murid Tuhan mengemban tugas pribadi yang disebut Amanat Agung, yang mana tugas ini mengharuskan setiap murid Tuhan untuk mengabarkan berita keselamatan kepada orang-orang yang belum percaya sampai kepada ujung bumi (Kis 1:8) (Sukmana and Suseno 2020). Hal ini merupakan tugas yang mulia karena amanat ini merupakan perintah yang Tuhan Yesus katakan secara langsung kepada muridmuridNya sebelum Ia naik ke surga. Penginjilan tidak dapat disepelekan karena tugas ini menyangkut banyak jiwa-jiwa terhilang yang juga dikasihi oleh Tuhan (Manurung 2005). Oleh karena itu sebagai seorang Kristen harus memiliki pandangan yang benar dan keyakinan yang benar dengan meyakini bahwa Yesus adalah satu-satunya Tuhan dan Juruselamat. Sebelum pergi dalam memberitaka Injil (Badai, Djeremod, and Keriapy 2020).

\section{Hakikat Misiologi}

Kasih Allah yang besar diberikan kepada manusia melalui pengorbanan Yesus Kristus di kayu salib, dan inilah yang menjadi dasar peran pendidikan Kristen dalam bermisi (sairin weinata 2010:12). Misiologi berasal dari kata Latin Missio adalah bentuk substantif dari kata kerja mittere (mitto, missi, missum) yang memiliki arti dasar yang majemuk yakni membuang, menembak, membenturkan, mengutus, mengirim, membiarkan, membiarkan pergi, melepaskan pergi, membiarkan mengalir". Selanjutnya, Camerling dan Wijaya mendefinisikan misi sebagai kegiatan untuk menyebarluaskan kabar keselamatan yang kemudian menjadi jemaat yang didasarkan 
pada pengutusan dan kelanjutnan misi (Camerling and Wijaya 2019). Dan juga kata misi memiliki arti penting makna yang harus dilakukan yaitu pengutusan. Dalam bahasa Jerman, bahasa Prancis, maupun bahasa Inggris istilah yang dipakai adalah mission. Ada sedikit perbedaan dalam bahasa Belanda digunakan dua istilah untuk menterjemahkan missio ini yaitu missie dan zending. Perbedaan istilah dalam bahasa Belanda ini dilatar belakangi oleh sinodial atau gereja yang mengunakan, kalau gereja Katolik mengunakan kata missie, sedangkan Gereja Protestan menggunakan kata zending (Sariman 2019).

Tugas yang diberikan oleh Tuhan kepada orang yang percaya untuk bersaksi tentang Kristus dalam perkataan dan perbuatan (Siagian 2016). Misi juga memiliki esensial yang harus diaktualisasi bahwa konsep penginjilan adalah memberikan kabar keselamatan yang hanya ada di dalam Kristus, yang kepadaNya dipanggil untuk bertobat, kemudian mendapatkan pengampunan dosa serta menjadikan mereka anggota keluarga Allah yang hidup bersama di dalam Roh Kudus (Bosch 2018:16).

Berdasarkan pengertian ini, misi merupakan usaha untuk menghadirkan kerajaan Allah di dunia melalui gereja, di mana Allah menghadirkan gereja bukan untuk memisahkan dirinya dari dunia, melainkan menjadi motor dalam penyelesaian masalah-masalah yang diterjadi di dalamnya sama seperti yang Yesus lakukan sewaktu Ia hidup. Sebab sejatinya misi bermakna keseluruhan tugas yang telah Allah berikan kepada Gereja demi keselamatan dunia (Siagian 2016). Euangelizo atau kabar baik itu juga kemudian dipakai oleh orang Kristen untuk menjelaskan barita tentang Yesus Kristus (Luk. 2:10; Efesus 3:8; 1 Kor 15:1-11), yang disebut dengan Injil atau kabar baik tentang Yesus Kristus (Tomatala 2004). Inilah inti dari isi amanat agung yang merupakan bagian dari kehidupan orang Kristen. karena Seorang Kristen dalam pengertian yang mendasar, kekristenan yang dimulai dari panggilan pertobatan hingga pada proses hidup baru, harus memahami dirinya sebagai agen dari misi Allah yang diekspresikan dalam seruan amanat agung (Munthe 2019), yang juga secara menyeluruh sebagai bagian dari gereja Tuhan.

\section{Misi dalam Pendidikan Kristen}

Pendidikan Kristen memiliki tujuan menjadikan manusia serupa dengan Kristus dalam pertobatan. Salah satu Origen's pedagogy menegaskan bahwa di akhir dari pendidikan adalah anak didik 
menjadi semakin serupa dengan Kristus (Seeley 1914). Pertobatan demikian penting dalam iman Kristen. Pertobatanlah yang menjadikan manusia semakin serupa dengan Kristus sehingga manusia dapat melihat Kerajaan Allah, yang kemudian mengalami kelahiran baru. Pendidikan agama Kristen juga membawa manusia pada pertumbuhan rohani yang akan terlihat dari dua aspek yaitu aspek vertikal dan horizontal (Sagala 2017). Nilai pendidikan Kristen yang tinggi harus diaktualisasikan dalam gereja sehingga menghasilkan landasan dan sebagai sarana orang percaya sebagai warga gereja untuk melaksanakan penginjilan terlebih diharapakan misi tersebut membawa pemahaman yang mampu menjadi semangat untuk terus dilakukan. Orang percaya juga diharapkan menempatkan misi pendidikan Kristen harus berdasar dan berakar pada Kristus (Boiliu 2016).

Dalam kegiatan pengajaran dan pembinaan gereja, gereja harus mengejawantahkan tiga tugas utama pengajaran Agama Kristen yaitu salah satunya Marturia (tugas kesaksian untuk memberitakan Injil) (Oci 2019) oleh karena itu pendidikan Kristen tidak dapat melepaskan diri dari tanggung jawab di masa yang akan datang untuk terus meregenerasikan anggota gereja atau orang percaya terus bermisi. Sehingga misi dalam Pendidikan Kristen memiliki dimensi misi eskatologis dalam tanggung jawabnya bagi masa kini dan yang akan datang (Kadarmanto 2020).

Konsep dasar peran Penginjilan ini hendaknya diajarkan oleh gereja kepada jemaat-jemaatnya dalam mempersiapkan pekerjaan Tuhan ini. Dan gereja membekali jemaatnya dengan memberikan pelatihan atau pengajaran yang membangkitkan semangat untuk dinyatakan dalam memberitakan kabar baik tersebut (Sukmana and Suseno 2020). Pendidikan Kristen diajarkan oleh gereja kepada jemaat dengan harapan, jemaat dapat dipersiapkan untuk menjadi murid dan pemimpin di masa depan yang memiliki jiwa Kristus. Maka terbentuklah sebuah komunitas misi masa kini yang berdampak dan gereja dikembalikan kepada keadaan semula, ini berarti bahwa gereja hidup sesuai dengan kehendak Allah yang mendirikan gereja sebagai sekumpulan orang percaya yang kemudian dikumpulkan untuk melakukan Amanat Agung sebagai tugas utama gereja hadir di dunia (Sukmana and Suseno 2020).

\section{Gereja dan Misi sebagai sumber Aktualisasi}

Di dalam Alkitab, diberitakan bahwa Allah mengutus gerejanya untuk menjalankan misi-Nya. Misi itu hadir dari hati Allah sendiri, yang kemudian 
ditanamkan pada hati umat-Nya, untuk menjangkau umat manusia secara global. Oleh karena itu, Allah memanggil gereja untuk menjalankan tugas besar ini (Amiman 2018). Hal inilah yang membuat misi gereja dan Amanat Agung dari Kristus bagian dua bagian berbeda pada satu koin. walaupun ada berbagai aliran dan denominasi gereja, Amanat Agung tersebut tetap berkaitan dengan tanggung jawab untuk bermisi, termasuk di dalamnya dipahami sebagai misi pemenangan jiwa (Manurung 2020). Misi harusnya tidak hanya dimiliki oleh denominasi gereja tertentu, melainkan merupakan tugas setiap gereja, tanpa memandang denominasi yang majemuk (Siagian 2016). Jika konsep dasar ini terpenuhi maka peran pendidikan Kristen akan menjadi gol dari pendidikan Kristen untuk membawa orang-orang yang dibimbing bertumbuh ke arah kedewasaan Kristus, yang tentu merupakan satusatunya jenis pendidikan yang layak dan dihargai oleh Allah sebab didasarkan pada ajaran-ajaran Kristus (2 Tim. 2:15)(Boiliu 2016). Karena dalam menjalankan pelayanan diharapkan gereja atau orang percaya secara personal semakin mencintai apa yang dilakukan dan di situ tentunya ada pengorbanan yang setiap hari dilakukan (Keriapy 2020).

Kegiatan misi untuk memenuhi Amanat Agung merupakan bagian penting yang tidak bisa dipisahkan dari kehidupan orang percaya maupun gereja Tuhan (Dwiraharjo 2019). Setiap umat Allah terlibat dalam pemberitaan kabar baik (Wiryadinata 2018). Sebab amanat tersebut dikumandangkan, sampai hari ini gereja Tuhan di mana saja, bersedia atau tidak bersedia, tidak dapat melepas tanggungjawab yang telah di perintahkan oleh guru Agung gereja, yaitu Yesus Kristus. Misi adalah tujuan utama jemaat; Membimbing dan melengkapi jemaat untuk mengemban misi adalah tugas utama pendeta; Tujuan utama pemberitaan Firman kepada jemaat ialah melatih dan memampukan jemaat melaksanakan peranannya dalam kegiatan misi; Dalam kaitan ini tujuan utama setiap pendeta ialah mencakapkan diri untuk tugas ini. Pendeta juga memiliki peran dalam memberdayakan jemaat untuk terlibat dalam kegiatan misi. Peran pendeta yang utama dapat melalui memberikan program pendidikan misionaris di jemaat lokal (Siahaya 2019). Dengan adanya pengajaran misi dan menempatkan misi sebagai sarana membangun dalam kehidupan berjemaat maka tugas dalam kehidupan masa kini yang dinamakannya dengan "time between", adalah kewajiban untuk memenuhi panggilan Allah dalam kehidupan nyata di dunia dan juga perwujudan misi (Kadarmanto 2020). Setiap orang Kristen yang percaya kepada 
Kristus, haruslah imannya dapat dilihat di tengah-tengah masyarakat - dunia (Sagala 2017). Namun peran penginjilan adalah sikap dan ketundukan kepada Yesus dengan memaknai bahwa penginjilan juga tidak lagi memaksakan orang untuk menjadi Kristen atau memeluk agama Kristen, tetapi berupa undangan yang disertai hormat dan kasih yang terbuka terhadap penolakan (Bangun 2015).

Yesus datang ke dalam dunia dengan membawa "mandat" khusus dari Bapa di Sorga, yakni menyelamatkan manusia dari belenggu dosa (Siahaya 2019). Dan dasar ini adalah pilihan yang harus dikerjakan sebagai orang percaya untuk menghidupi sebuah amanat bahwa orang percaya dipanggil untuk menjadi berkat bagi orang lain, dipanggil untuk menjadi garam dan terang dunia (Manaransyah 2015). Untuk itu Semua manusia termasuk orang awam memiliki tugas pengutusan, tidak terbatas pada gereja, karena pada dasarnya misi adalah milik Allah yang ditegaskan dengan Missio Dei atau pengutusan dari Allah yang menghendaki keselamatan bagi semua orang. Jadi gereja hanya mendapat misi dan bukan pemilik misi (Banawiratma 2006). Seperti yang disampaikan oleh rasul Paulus bahwa Kristus telah mati menebus dosa manusia (1 Kor 15:3-4). Namun peran jemaat dalam melakukan misi harus memberitakan Yesus sebagai inti dan sumber misi yang benar karena akan berakibat menentang pemberi misi (Galatia 1:9).

Pertumbuhan gereja sebagai dasar dari menghidupi kebenaran Allah harus dinyatakan dengan mengaktualisasi peran gereja untuk mendasari pendidikan gereja untuk mencapai setiap pribadi memberikan dedikasinya dalam menyampaikan pesan keselamatan kepada semua orang lewat pendidikan gereja yang terus digalakkan dan dapat dicapai menuju penggenapan mandat amanat Agung. untuk itu peran gereja melalui misi penginjilan harus menjadi prioritas (Manurung 2020). Faktor yang dapat meningkatkan pertumbuhan gereja adalah dengan menjalankan Amanat Agung (Hartono 2018). Gereja harus memberdayakan jemaat Tuhan dengan karunia Roh Kudus yang dapat menjawab kebutuhan pelayanan misi di sepanjang perjalanan gereja dalam membangun regenerasi melakukan misi amanat agung merupakan tugas gereja secara umum, yang harus dilakukan oleh semua orang percaya (Munthe 2019). Terlebih dalam pertumbuhan gereja Tuhan yang harus terus maju sebab gereja Tuhan memiliki tanggung jawab untuk melakukan pekerjaan yang Tuhan berikan kepada mereka. Namun demikian, dalam rangka untuk mengerjakan panggilan tersebut 
Allah memberikan kemampuan yang mungkin di luar apa yang bisa dilakukan seseorang. Karunia setiap orang berbedabeda sesuai dengan kebutuhan dan keadaan yang ada di dalam gereja atau tempat di mana seseorang dipanggil untuk melayani (Munthe 2019). Melalui pandangan Paradigma misi 'modern' yang benar sangat dipengaruhi oleh pikiran pencerahan yang dilakukan oleh pemimpin rohani dalam gereja untuk memotivasi dan memberikan pemahaman paradigma 'modern' serta tujuan utama misi adalah penambahan anggota gereja, church growth (Jong 2007). Walaupun gereja ada ditengah dan diantara pluralitas agama dan kebudayaan yang mewarnai masyarakat masa kini, sehingaa peran gereja harus bertugas untuk mewartakan Injil (Hariprabowo 2009). Tugas misionaris adalah tugas semua orang percaya. Kristus menugaskan sendiri kepada gereja- Nya, orang-orang percaya, untuk mengabarkan Injil "sampai ke ujung bumi" kepada "semua bangsa" sampai kepada "akhir zaman" dengan kuat kuasa dari kehadiran Kristus yang disalibkan dan bangkit dalam Roh dalam kehidupan dunia dan gereja-Nya (Mrk 1:17; 3:14; $16: 15-16$; Kis $1: 8 ; 1$ Kor $1: 17,23)$ (Andriani 2013). Karena dari hal ini seharusnya makna penginjilan menempatkan Kristus yang menjadi sentral dalam pengajaran yang diaktualisasi dalam misi (Tampenawas, Ngala, and Taliwuna 2020).

\section{KESIMPULAN}

Berdasarkan pemahaman dan uraian di atas tentang pendidikan Kristen dalam gereja sebagai dasar dan sarana aktualisasi misi Kristen, ada tanggung jawab dan keharusan orang yang percaya kepada Tuhan untuk Menginjil. Kehadiran gereja di dunia bukan untuk melepaskan diri atau menjauhkan diri dari dunia, melainkan ada satu tugas besar yang Allah berikan, yakni Amanat Agung. Oleh karena itu, dapat disimpulkan bahwa pendidikan Kristen harus dimulai dengan pengertian yang berkaitan terhadap hakikat Misiologi sebagai dasar dan penggerak dalam melakukan misi. Selanjutnya, misi dalam Pendidikan Kristen juga harus menjadi kurikulum yang terus diajarkan untuk meregenerasi jemaat Tuhan untuk terus mengaktualisasi mandat Amanat Agung. sehingga Gereja dan Misi sebagai sumber Aktualisasi dapat terwujud dan menjadi gaya hidup orang percaya sebagai bagian dari gereja. Oleh karena itu, solusi yang penting untuk penulis bisa berikan adalah gereja perlu menambahkan kurikulum misi baik dalam katekisasi maupun dalam pengajaran-pengajaran seperti PA (Pendalaman Alkitab). 
DAFTAR PUSTAKA

Amiman, Ramona Vera. 2018. "Penatalayanan Gereja Di Bidang Misi Sebagai Kontribusi Bagi Pelaksanaan Misi Gereja." Missio Ecclesiae 7(2):164-87.

Andriani, Sarah. 2013. "Refleksi Guru Pendidikan Agama Kristen Sebagai Misionaris Di Dalam Pendidikan." Jurnal Antusias: Jurnal Teologi Dan Pelayanan 2(4):1-16.

Arifianto, Yonatan Alex, Wulan Agung, and Setya Budi Tamtomo. 2020. "Membangun Paradigma Tentang Misi Sebagai Landasan Dan Motivasi Untuk Mengaktualisasi Amanat Agung." Sabda: Jurnal Teologi Kristen 1(2):131-41.

Arifianto, Yonatan Alex, Kristien Oktavia, and Matius I. Totok Dwikoryanto. 2020. "Studi Teologis Prinsip Penginjilan Paulus Dalam 1 Korintus 9:16." LOGIA: Jurnal Teologi Pentakosta 2(1):22-41.

Arifianto, Yonatan Alex, Reni Triposa, and Paulus Karaeng Lembongan. 2020. "Bible Study of Mission and Discipleship in the Great Commission and Its Implications for Today's Christian Life." Diegesis: Jurnal Teologi 5(2):25-42.

Badai, Kristian, Kaleb Djeremod, and Frets Keriapy. 2020. "Penginjilan
Sebagai Upaya Meneguhkan Keyakinan Keselamatan Anak.” HARVESTER: Jurnal Teologi Dan Kepemimpinan Kristen 5(2):120-34. Banawiratma, J. B. 2006. "Misi, Globalisasi Dan Kaum Miskin Di Indonesia." Jurnal Teologi Proklamasi 8(8):42.

Bangun, Maraike Joanna Belle. 2015. "Menantang Paradigma Misi Kristen Yang Bersifat Kognitif-Proposisional Dengan Mengembangkan Pengetahuan Historis Misi.” Indonesian Journal of Theology 3(1):77-93.

Boiliu, Noh Ibrahim. 2016. "Misi Pendidikan Agama Kristen Dan Problem Moralitas Anak." Jurnal Pendidikan Agama Kristen (Regula Fidei) 1(1):115-40.

Bosch, David J. 2018. Tranformasi Misi Kristen, Sejarah Teologi Misi Yang Mengubah Dan Berubah. Jakarta: BPK Gunung Mulia.

Camerling, Yosua Feliciano, and Hengki Wijaya. 2019. "Misi Dan Kebangkitan Rohani: Implikasi Misi Allah Bagi Gereja." Jurnal Ilmiah Religiosity Entity Humanity (JIREH) 1(1):57-71.

David Sills. 2011. Panggilan Misi. surabaya: Momentum.

Dwiraharjo, Susanto. 2019. "Kajian Eksegetikal Amanat Agung Menurut 
Matius 28: 18-20." Jurnal Teologi Gracia Deo 1(2):56-73.

Hariprabowo, Y. 2009. "Misi Gereja Di

Tengah Pluralitas Agama Dan

Budaya." Jurnal Orientasi Baru 18(1):33-50.

Hartono, Handreas. 2018.

"Mengaktualisasikan Amanat Agung

Matius 28:19-20 Dalam Konteks Era

Digital.” Kurios 4(2):157-166.

Hutahaean, Tumpal H. 2019. "Signifikansi

Apologetika Dalam Penginjilan.”

Stulos 17(1):54-74.

Jong, Kees de. 2007. "Misiologi Dari

Perspektif Teologi Kontekstual.”

Gema Teologi 31(http://journaltheo.ukdw.ac.id/index.php/gema/issu e/view/5).

Kadarmanto, Mulyo. 2020. “Dimensi Misi

Eskatologis Dalam Pendidikan

Kristen.” REGULA FIDEI: Jurnal

Pendidikan Agama Kristen 5(1):69-

81.

Keriapy, Frets. 2020. "Pendidikan

Kristiani Transformatif Berbasis

Multikultural Dalam Konteks

Indonesia." REGULA FIDEI: Jurnal

Pendidikan Agama Kristen 5(2):82-

93.

Konaniah, Albert. 2018. "Sekolah Teologi

Dan Gerakan Penginjilan." Veritas :

Jurnal Teologi Dan Pelayanan.

Manaransyah, Awasuning. 2015.

"Keluarga Kristen Yang Diberkati
Tuhan: Observasi Terhadap Mazmur 133:1-3." Misso Ecclesiae 4(April):28-34.

Manurung, Kosma. 2020. "Efektivitas Misi Penginjilan Dalam Meningkatkan Pertumbuhan Gereja." DUNAMIS: Jurnal Teologi Dan Pendidikan Kristiani 4(2):225-33.

Manurung, Manto. 2005. Penginjilan Di Tengah Masyarakat Majemuk: Tantangan Dan Solusinya. Jakarta: Sekolah Tinggi Teologia Ekklesia. Munthe, Eben. 2019. "Mengoptimalkan Karunia Dalam Jemaat Untuk Melakukan Misi Amanat Agung Di Era 4.0.” EPIGRAPHE: Jurnal Teologi Dan Pelayanan Kristiani $3(2): 133$.

Oci, Markus. 2019. "Implikasi Misiologi Dalam Pengembangan Kurikulum Agama Kristen Di Gereja Lokal.” FIDEI: Jurnal Teologi Sistematika Dan Praktika.

Ott, Craig, Stephen J. Strauss, and Timothy C. Tennent. 2010. Encountering Theology of Mission: Biblical Foundations, Historical Development and Contemporary Issues. Michigan: Baker Academic. panuntun, daniel fajar. 2020. "Misi Apologetika Kristen Online Di Era Diruspsi.” Jurnal Apostolos 2(1):8. Purwoto, Paulus, Hardi Budiyana, and Yonatan Alex Arifianto. 2020. 
"Landasan Teologis Pendidikan

Kristen Dalam Perjanjian Baru Dan

Relevansinya Bagi Pendidikan

Kristen Masa Kini.” DIDAKTIKOS:

Jurnal Pendidikan Agama Kristen 3(1):34-48.

Purwoto, Paulus, and Asih Rachmani

Endang Sumiwi. 2020. "Pola

Manajemen Penginjilan Paulus

Menurut Kitab Kisah Para Rasul 9-

28." Angelion Jurnal Teologi Dan

Pendidikan Kristen 1(2):113-31.

Randan Bua, Piter, David Samiyono, Tony

Christian Tampake, Fakultas

Teologia, and Universitas Kristen

Satya Wacana. 2019. "Misi Gereja

Dalam Mewujudkan Keadilan Sosial:

Sebuah Perspektif Dari Sila Kelima

Pancasila." Copyright@ 5(2):109-24.

S., Denney Andrew, and Richard Tewksbury. 2013. "'How to Write a

Literature Review,." Journal of Criminal Justice Education 24(2):218-234.

Sagala, Lenda Dabora. 2017. "Peran Pendidikan Agama Kristen Dalam Menghadapi Perubahan Sosial.” Jurnal Simpson: Jurnal Teologi Dan Pendidikan Agama Kristen.

sairin weinata. 2010. Identitas \& Ciri Khas Pendidikan Kristen Di Indonesia. jakarta: BPK Gunung Mulia.

Sariman, Silas. 2019. "Strategi Misi
Sadrach Suatu Kajian Yang Bersifat

Sosio Historis." Jurnal Abdiel:

Khazanah Pemikiran Teologi,

Pendidikan Agama Kristen, Dan

Musik Gereja 3(1):17-32.

Seeley, Levi. 1914. History of Education.

American Book Company.

Sengkoen, Jefri Frit. 2020. "Pembelajaran

Pendidikan Agama Kristen Sebagai

Sarana Misi Bagi Pemuda."

APOLONIUS: Jurnal Teologi Dan

Pendidikan Kristen 1(2):23-33.

Siagian, Fredy. 2016. "Rekonstruksi Misi

Gereja Di Abad 21." Syntax Literate 1(4):1-13.

Siahaya, Johannis. 2019. "Misi Dalam

Doa Yesus Menurut Yohanes 17.”

Jurnal Teruna Bhakti 1(2):64-74.

Stevanus, Kalis. 2020. "Karya Kristus

Sebagai Dasar Penginjilan Di Dunia

Non-Kristen." Fidei: Jurnal Teologi

Sistematika Dan Praktika 3(1):1-19.

Sukmana, Daniel Gerri Tedja, and Aji

Suseno. 2020. "Penginjilan Dalam

Konteks Pendidikan Agama Kristen

Di Tengah Masyarakat Majemuk."

DIDAKTIKOS: Jurnal Pendidikan

Agama Kristen 3(2):72-83.

Sunquist, Scott W. 2013. Understanding

Christian Mission Participation in

Suffering and Glory. Michigan:

Baker Academic.

Susanta, Yohanes Krismantyo. 2020.

"Menuju Misi Kristen Yang 
Mengedepankan Dialog Antariman."

THRONOS: Jurnal Teologi Kristen $1(2): 73-85$.

Tampenawas, Alfons Renaldo, Erna Ngala, and Maria Taliwuna. 2020. "Teladan Tuhan Yesus Menurut Injil Matius Dan Implementasinya Bagi Guru Kristen Masa Kini.” EDULEAD: Journal of Christian Education and Leadership 1(2):21431.

Tomatala, Yakob. 2004. Penginjilan Masa

Kini 1. Malang: Gandum Mas.

Umrati, and Hengki Wijaya. 2020.

Analisis Data Kualitatif Teori Konsep Dalam Penelitian

Pendidikan. Sulawesi Selatan:

Sekolah Tinggi Theologia Jaffray.

Wiryadinata, Halim. 2018. "Mission And

Evangelism: African Context."

Kurios 3(1):1.

Wongso, Peter. 1981. Tugas Gereja Dan

Misi Masa Kini. Surabaya: Yakin. 